\title{
Penetration of ultraviolet radiation into shallow water sediments: high exposure for photosynthetic communities
}

\author{
Ferran Garcia-Pichel*, Brad M. Bebout** \\ Max Planck Institute for Marine Microbiology, Fahrenheitstraße 1, D-28359 Bremen, Germany
}

\begin{abstract}
Benthic pholosynthetic microorganisms are widespread in shallow-water sediments, microenvironments that are commonly assumed to be virtually opaque to ultraviolet radiation (UVR). We used a newly developed optical microprobe to measure the submillimeter penetration of solar UVR into a variety of these microenvironments. UVR trapping due to strong scattering occurred at the surface of some sediments, resulting in a surface maximum of scalar irradiance $\left(E_{0}\right)$ that could be significantly larger that the incident radiation. In the subsurface, $E_{0}$ was typically extinguished in a quasiexponential manner, with attenuation coefficients $\left(310 \mathrm{~nm}\right.$ ) ranging from 4 to $21 \mathrm{~mm}^{-1}$, depending on sediment type. Ultraviolet $B$ (at $310 \mathrm{~nm}$ ) was extinguished to $1 \%$ of the incident between 1.25 and $0.23 \mathrm{~mm}$ from the surface. Within the euphotic zones of these sedinients, however, the space-averaged UVB scalar irradiance was very high, between 15 and $33 \%$ of the incident. In natural waters, for example, the same parameter varies between 3 and $9 \%$ of the incident. Thus, in fact, photosynthesis in these environments must develop under strong UV stress, and it must be regarded as potentially labile to the effects of ozone depletion.
\end{abstract}

KEY WORDS: Sediments - Ultraviolet radiation - Prımary productivity

\section{INTRODUCTION}

Shallow-water and intertidal sediments, both fresh water and marine, are usually colonized by phototrophic microorganisms. Since visible light is strongly attenuated in these microenvironments, photosynthesis can occur typically only within millimeters from the surface (Jørgensen \& Des Marais 1988, Lassen et al. 1992, Kühl \& Jørgensen 1994). In spite of this, the benthic phototrophic microbial communities serve a crucial ecological function, contributing significantly to local productivity (Van Raalte et al. 1976, Pinckney \& Zingmark 1993), and decreasing sediment erosion (Grant \& Gust 1987, Patterson 1994). Solar ultraviolet $B$ radiation (UVB; 280 to $315 \mathrm{~nm}$ ) can in principle damage the photosynthetic apparatus of microalgae and cyanobacteria, but the actual impact of UVB on

\footnotetext{
·E-mail: ferran@postgate.mpi-mm.uni-bremen de

- Present address: Horn Point Environmental Laboratory, PO Box 775. Cambridge, Maryland 21613, USA
}

natural communities is clearly, among other variables, a function of in situ exposure. It is commonly assumed that ultraviolet radiation (UVR) does not penetrate significantly into sedimentary microenvironments, which have in fact been regarded as an effective refuge from UV exposure (Margulis et al. 1976). However, sediment microalgae may produce large quantities of UV-sunscreen compounds (GarciaPichel \& Castenholz 1991, 1993) and, at least in some of these communities, several biological processes can be affected by natural UVB exposure (Bothwell et al. 1994, Garcia-Pichel \& Castenholz 1994). These observations cannot be easily explained if exposure occurs only at the virtual surface, but no measurements of the penetration of UV into sedimentary environments were available. For this reason, we recently developed a fiber optic microprobe which made the measurement of UV scalar irradiance $\left(E_{0}\right)$ possible at a spatial resolution of ca $0.1 \mathrm{~mm}$ (GarciaPichel 1995), and used it to measure the UV radiative fields within shallow-water sediments on which we report here. 


\section{MATERIAL AND METHODS}

Samples. All measurements were performed in the laboratory with freshly collected samples. North Sea samples were collected using PVC corers and transported within several hours to the laboratory. Overseas samples were air-lifted and reached the laboratory within 2 to $3 \mathrm{~d}$ of collection. Samples were incubated in water from the site, or in artificial seawater made up to the local salinity conditions, at room temperature in small acrylic flumes. Samples were illuminated from above at $200 \mu \mathrm{mol}$ photon $\mathrm{m}^{-2} \mathrm{~s}^{-1}$ of PAR (photosynthetically active radiation, by convention 400 to $700 \mathrm{~nm})$, until measurement. Measurements were made on core subsamples $(5$ to $7 \mathrm{~cm}$ in diameter, 3 to $10 \mathrm{~cm}$ deep. A brief description of each sample follows: Sample 1: fine beach quartz sand, washed and with a grain size of around $250 \mu \mathrm{m}$; Sample 2: natural intertidal carbonate sand crust, harboring a low-density community of diatoms and cyanobacteria (Bahamas); Sample 3: upper intertidal sandy cyanobacterial mat, Sandwatt, from Norderney Island (German Wadden Sea); Sample 4. shallow-water sediment from the Bay of Aarhus (Denmark), composed of benthic diatoms in a matrix of allochthonous opal and organic detritus; Sample 5: hypersaline, virtually organic, cyanobacterial mat from Solar Lake, Sinai, Egypt; Sample 6: silty intertidal mud. Schlickwatt, from the Wadden Sea near Dorum (Germany)

Optical measurements. Core samples were illuminated from above with a $200 \mathrm{~W}$ Xe arc-lamp illuminator (Oriel Corp., Connecticut, USA). The lamp beam was collimated through a quartz condenser and reflected on a UV dichroic mirror so that the exiting beam (ca $5 \mathrm{~cm}$ in diameter) was collimated and highly enriched in UVB wavelengths. This set-up resulted in minimal effects of stray light signals in our measurement system (see 'Results') since, for any given spectrum, signals normally fell within 1 order of magnitude across the wavelength range 270 to $700 \mathrm{~nm}$, even for spectra measured deep into the sediment.

Measurements of penetration of UVR and visible light were carried out with custom-huilt scalar irradiance microprobes with a sensing tip 80 to $105 \mu \mathrm{m}$ in diameter The microprobes consisted of a tapered optical fiber with a UV-transparent vitroceramic tip diffuser, which was inserted into the samples at a $45^{\circ}$ angle to the vertical using micromanipulators. The construction and use of the microprobes was described in detail elsewhere (Garcia-Pichel 1995). All operations were carried out under visual monitoring through a dissecting microscope focused on the sediment surface. Light collected by the microprobe was transmitted through the optical fiber, collimated at the opposite end and focused onto an IL 1785 (Interna- tional Light 1785) spectroradiometer, which we modified to couple the fiber optic input. For the measurement of UVB profiles with depth, the spectrorradiometer was set at $310 \mathrm{~nm}$. For spectral measurements, we used a step size of $5 \mathrm{~nm}$ in the UV and of either 5 or $10 \mathrm{~nm}$ in the visible. The absence of stray light signals was checked using long-pass optical filters in the light source and spectrophotometer. The incident (beam) irradiance was determined by exchanging the subject with a black, nonreflecting well, maintaining the microprobe in place with respect to the beam. All data obtained are expressed here as a percentage of this parameter.

Optical parameters. The probes used measured scalar irradiance, $E_{0}$, or the radiation incident on a point in space from all directions in the solid angle, much like a typical $4 \pi$ sensor would. In highly scattering systems, such as sediments, it is important to measure this parameter because incident radiation becomes rapidly diffuse. $E_{0}$, also known as fluence rate or space irradiance, probably approximates the radiation to which the microorganisms are exposed better than other optical parameters, such as downwelling irradiance (see Kirk 1983, Kühl \& Jørgensen 1994).

Subsurface attenuation coefficients of the scalar irradiance in the UVB, $K_{D}($ UVB), were calculated directly from the profiles $(310 \mathrm{~nm})$ using data below $100 \mu \mathrm{m}$ depth only, to avoid the surface light-trapping zones. For this we used linear regression of the ln-transformed mean values at each depth. The correlation coefficients were $>0.98$ in all cases. The depth at which incident UVB was attenuated to $1 \%$ of the incident, $Z_{1} \ldots((\cup \vee B)$, was determined by interpolation in the regression line. The depth of the euphotic zone, $Z_{1}$ (vis), was calculated from spectral measurements within the visible range (400 to $700 \mathrm{~nm}$ ). For this, the spectral measurements were integrated to obtain attenuation profiles of visible light assigning equal weights to all wavelengths. From the averaged profiles, averaged $K_{D}$ (vis) and $Z_{1}$ (vis) were obtained in the same way as for the UVB profiles above. We note that the latter 2 parameters, because they average broadband radiation, are actually a function of the spectral composition of the incident light, and thus may vary somewhat under different spectral conditions.

As a means to compare the overall exposure for the phototrophic organisms, we calculated the spaceaveraged mean UVB scalar irradiance within the euphotic zone, $\bar{E}_{0}^{\text {eus }}$ (UVB), which is defined as

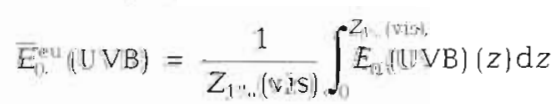

where $\bar{E}_{0)}^{\text {eu }}(\mathrm{UVB})(z)$ is the distribution of the UVB scalar irradiance with depth and $z$ is depth, and was calculated as 


$$
\bar{E}_{0}^{\mathrm{eu}}(\mathrm{UVB})=\frac{1}{n} \sum_{1}^{n} E_{0}(\mathrm{UVB})(z)
$$

where $E_{0}^{\mathrm{eu}}(\mathrm{UVB})(z)$ is each of the measured values of $E_{0}$ in the UVB profile that fell within the euphotic zone of the sediment, and $n$ is the total number of such values.

Because the attenuation of UVR was in all cases stronger than that in the visible, the ratio of UV to visible decreased with depth. This may have implications for the in situ photobiology of the microorganisms, since a progressive 'refuge' from ultraviolet exposure may be gained by avoiding the surface zones if enough visible light for photosynthesis is available at depth. The dimensionless parameter, $R$, was designed as a means to compare the depth-refuge effect in different environments. It is defined, and calculated, as

$$
R=\left[K_{D}(\mathrm{UVB})-K_{D}(\mathrm{vis})\right]\left[K_{D}(\mathrm{vis})\right]^{-1}
$$

It takes positive values whenever the attenuation of UVB is stronger than that of visible, and it becomes larger as the difference in attenuation coefficients between UVB and visible grows. By normalizing to the attenuation coefficient of the visible, the parameter becomes dimensionless and environments of different (optical) depths can be readily compared. Environments with a high value of $R$ will offer a significant depth-refuge from UV exposure, and vice versa. We note that, because the exponential extinction of $E_{0}$ occurs only at the subsurface, this parameter cannot satisfactorily describe the zones where light trapping occurs.

\section{RESULTS}

Depth profiles for $E_{0}$ in the UVB, in samples ranging from organic-free mineral to virtually organic, are pre- sented in Fig. 1 The optical parameters are presented in Table 1 Incident UVB was strongly attenuated in all samples (100-fold within $1.3 \mathrm{~mm}$ or less). The build-up of a surface $E_{0}$ maximum, a light-trapping effect due to scattering, typical in strongly scattering media (Vogelmann \& Björn 1986, Jørgensen \& Des Marais 1988), and the apparently exponential extinction of $E_{0}\left(R^{2}\right.$ always $>0.98$ for $\ln$-transformed mean data) below 100 to $200 \mu \mathrm{m}$, defined the shape of the profiles. Surface maxima $\left[E_{0}(\mathrm{UV} B), z=0\right]$ ranged from insignificant in silty and highly organic samples to values $157 \%$ higher than the incident irradiance in carbonate sand crusts. Subsurface exponential extinction occurred with apparent diffuse attenuation coefficients ranging from 4.1 in wet, clean quartz sand to $21.6 \mathrm{~mm}^{-1}$ in silty mud (Table 1). The values of $\bar{E}_{0}^{e u}$ (UVB) calculated for these sedimentary microenvironments ranged between $15 \%$ of the incident irradiance in wet sand to $25 \%$ of the incident irradiance in carbonate sand and $33 \%$ of the incident in silty mud; these values were not well correlated with their respective UVB attenuation coefficients. $\bar{E}_{0}^{\text {eu }}$ (UVB) values attained in sediments were invariably much higher than those calculated for natural waters (also presented in Table 1), which varied between 3 and $9 \%$ of incident for a range of optically diverse localities.

Spectral determinations showed (Fig 2) that there was a general marked trend of increased attenuation with decreasing wavelength. Whereas this occurred in all cases (not all data shown), spectral signatures for photosynthetic pigments (particularly chlorophyll a) were sometimes clear wherever microalgal populations were present at sufficient densities. Spectral signatures for mycosporine-like amino acid derivatives, thought to act as UV-sunscreen compounds, may have been responsible for the spectral signatures in the UVB
Fig. 1 Profiles of UVB (310 nm) scalar irradiance within sedimentary environments Means and standard deviations of 4 to 5 profiles at different locations in each sample are shown. Inserted boxes identify each sample with a short name and the sample number (see 'Materials and methods' and Table 1 for further information). In each panel, the upper horizontal line represents the (approximate) surface and the lower line the depth at which the visible light ( 400 to $700 \mathrm{~nm}$ ) was attenuated to $10 \%$ of the incident $(1 / 2$ of the euphotic zone), which was determined separately from data such as those in Fig. 2

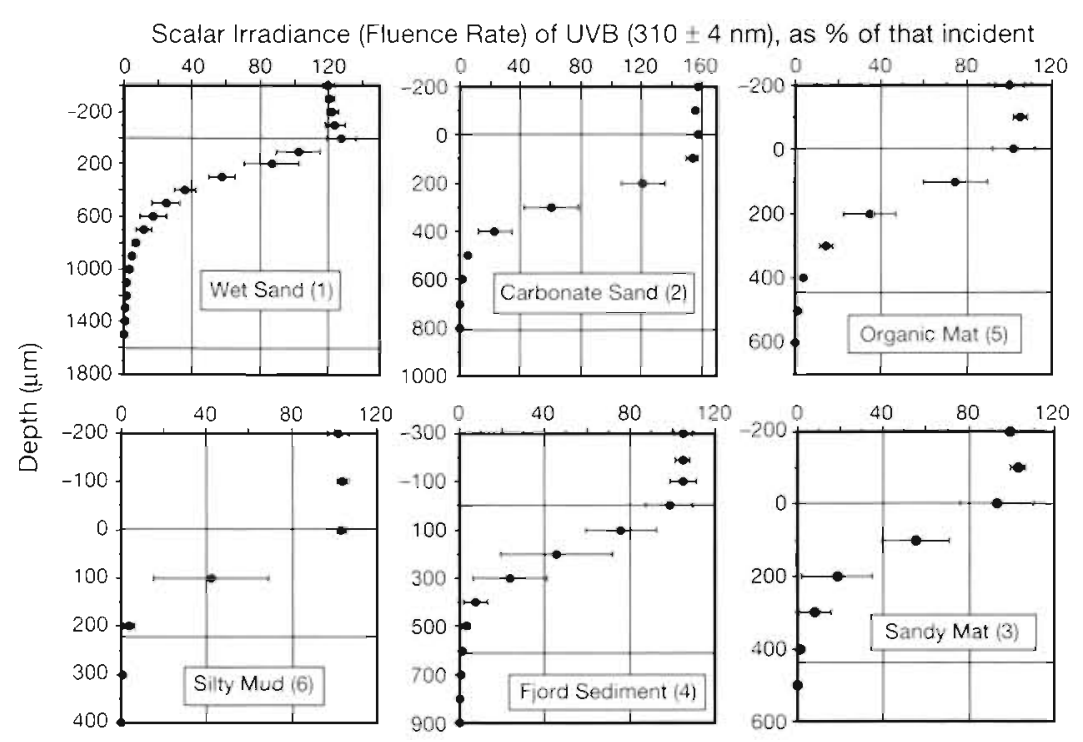


Table 1. Optical characteristics of sediments and waters. See 'Matenals and methods' for sample details and parameter definitions. For waters, the optical parameter measured was downwelling irradiance, not scalar irradiance; in natural waters scalar irradiance was only slightly larger than downwelling irradiance

\begin{tabular}{|c|c|c|c|c|c|c|}
\hline Characteristics & 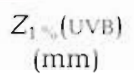 & $\begin{array}{c}Z_{i} \text { (vis) } \\
(\mathrm{mm})\end{array}$ & $\begin{array}{c}\bar{E}_{0}{ }^{e u} \text { (UVB) } \\
(\% \text { incident })\end{array}$ & $\begin{array}{l}E_{0}(\text { UVB } ; z=0) \\
(\% \text { incident) }\end{array}$ & $\begin{array}{l}K_{D}(\text { UVB }) \\
\left(\mathrm{mm}^{-1}\right)\end{array}$ & $R$ \\
\hline \multicolumn{7}{|l|}{ Sediments } \\
\hline 1. Fine beach sand (wet) & 1.25 & 3.10 & 15 & 127 & 4.1 & 1.56 \\
\hline$(\mathrm{dry})$ & 0.98 & 2.40 & 23 & 131 & 6.5 & 1.62 \\
\hline 2. Carbonate sand crust & 0.64 & 2.41 & 22 & 157 & 12.1 & 3.97 \\
\hline 3. Sandy intertidal mat & 0.36 & 0.72 & 24 & 103 & 17.2 & 1.28 \\
\hline 4. Diatom/opal fjord sediment & 0.65 & 1.23 & 18 & 98 & 7.9 & 0.88 \\
\hline 5. Cyanobacterial mat & 0.50 & 0.95 & 25 & 105 & 10.5 & 0.75 \\
\hline 6. Silty intertidal mud & 0.23 & 0.45 & 33 & 103 & 21.6 & 0.94 \\
\hline \multicolumn{7}{|l|}{ Waters } \\
\hline Sarqasso Sea a & $25 \times 10^{3}$ & $150 \times 10^{3}$ & 6 & - & $0.12 \times 10^{-3}$ & 2.8 \\
\hline \multirow{2}{*}{ Southern Ocean' } & $17 \times 10^{3}$ & $120 \times 10^{3}$ & 3 & - & $0.26 \times 10^{-3}$ & 5.9 \\
\hline & $16 \times 10^{3}$ & $63 \times 10^{3}$ & 6 & - & $0.28 \times 10^{-3}$ & 2.8 \\
\hline Admiralty Bay (Antarclica) ${ }^{c}$ & $22 \times 10^{3}$ & $44 \times 10^{3}$ & 6 & - & $0.26 \times 10^{-3}$ & 1.0 \\
\hline Dutch Wadden Sea & $1 \times 10^{3}$ & $3 \times 10^{3}$ & 9 & - & $4.60 \times 10^{-3}$ & 2.5 \\
\hline \multicolumn{7}{|c|}{$\begin{array}{l}\text { 'Calculated from spectral attenuation coefficients (Smith \& Baker 1981) } \\
\text { 'Data from Helbling et al. (1994) gathered at } 2 \text { different stations near Elephant Island. } Z_{1} \text { (vis) is from measured values } \\
\text { 'Data from Vosjan \& Pauptit (1992). Measurements of 'visible' included infrared wavelengths, which are strongly absorbed in } \\
\text { water, so } Z_{1} \text { (vis) is probably underestimated and, consequently, } \bar{E}_{0}^{\text {eu }} \text { (UvB) and } R \text { are probably overestmated. } Z_{1} \text { "... (vis) is } \\
\text { from measured values }\end{array}$} \\
\hline
\end{tabular}

region that we found in densely populated cyanobacterial mats (Sample 3), and thus such sunscreens may have contributed significantly to the extinction of UVB in these systems

The parameter $R$, which is high in those environments in which UVB is strongly attenuated relative to

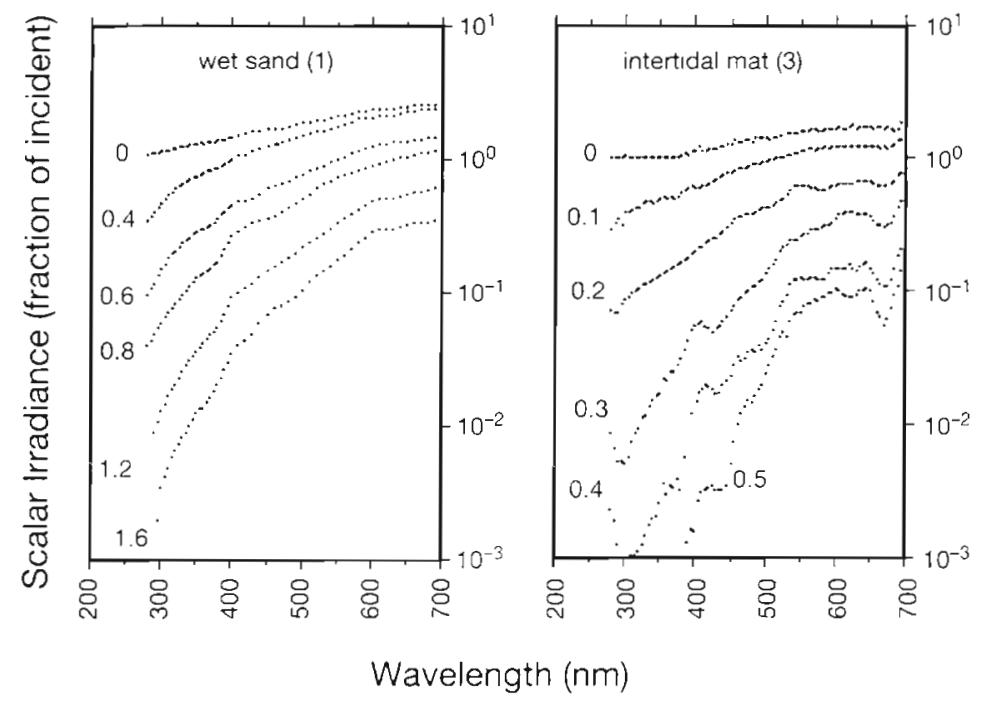

Fig. 2. $E_{0}(\lambda)$ at selected depths in sedimentary benthic environments. The depth corresponding to each spectrum is noted at the left end. In sand (Sample 1), a rather featureless increase of attenuation with decreasing wavelength occurred. In the sandy mat (Sample 3), the spectral signatures for photosynthetic pigments are superimposed on this general increase. A signature for mycosporine-like amino acids may be responsible for the maximum in attenuation at $c a 300$ to $310 \mathrm{~nm}$ in the intertidal mat visible and which gauged the depth-refuge from UVB exposure, varied around 1 in most sedimentary samples, indicating that UVB was attenuated approximately twice as strongly as the averaged visible. The carbonate sand crust had a much higher value, and UVB was attenuated in the subsurface close to 5 times as strongly as the visible. The depth-refuge effect tended to be larger in waters than in sediments; it was, however, very much environment-specific. Interestingly, the lowest $R$ values were found in highly organic samples (i.e. cyanobacterial mats), which may have had to do with the increased attenuation of visible light due to their high concentrations of photosynthetic pigments

\section{DISCUSSION}

The range of sediments studied were diverse with respect to the attenuation of UVR, from silty mud sediments being the most absorbant (Sample 6) and quartz sand. the least (Sample 1), paralleling their optical characteristics in the visible. Carbonate sand sediments seemed to behave rather differently than sandy, silty and organic sediments, in that both light trapping and differential extinction of UV with respect to visible were very strong. This may have 
been due to the fact that each carbonate particle scatters light through diffuse surface reflectance (each particle has a lot of microstructure and many refraction events may occur within each one), rather than through multiple refraction, as it might occur with living cells or quartz particles. Thus, carbonate sand sediments may offer a stronger refuge from UVB exposure in the deeper layers of the euphotic zone than do sandy or organic sediments.

In clear waters, absorptive losses dominate the attenuation of radiation, and water absorption is significantly larger in the UV than in the visible. In sediments, however, both scattering and absorption processes contributed significantly to attenuation. The magnitude of scattering losses is manifest in the differences found between wet and dry sand. The difference in refractive index between particles and interstitial medium, largely responsible for the scattering of light, is larger in dry than in wet sand. Since scattering is strongest in dry sand, UVB penetrated less (Table 1). But because the radiation lost though scattering to the vertical path is not immediately lost to the system, but contributes to the (diffuse) fluxes at other nearby points, the average scalar irradiance within the system was actually higher in dry sand (Table 1). This phenomenon is responsible for the near-surface maxima, or light-trapping effect, which occurred in some sediments. These effects were considerably weaker in the UVB than in the UVA, and even weaker than in the visible in the same samples (Fig 2), as well as in other sediments and mats (Lassen et al. 1992, Kühl \& Jørgensen 1994), so that the ratios of UVB and UVA to PAR in the light-trapping surface zone, and, thus, at all depths, were smaller than those in the incident radiation. Additionally, the high concentration of photosynthetic pigments in some of these communities resulted in strong attenuation of visible light, in effect narrowing the euphotic zone. Both the near-surface UV lighttrapping effects and the strong attenuation of visible light are probably responsible for the comparatively high levels of exposure measured in the euphotic zones of sedimentary microenvironments.

Studies have identified significant decreases of primary productivity attributable to present-day solar UVB on planktonic photosynthetic communities (Smith et al. 1992, Holm-Hansen et al. 1993). Provided that UV sufficiently penetrates the overlaying waters, one should expect a much more marked impact of UVB on the metabolically analogous communities living in sediments, based only on the optical characteristics of their microenvironments. Indeed, in ir radiation experiments, we could detect UVB-induced photodamage to photosynthesis in several of these communities, both at the surface and in the subsurface (Babout \& GarciaPichel 1995). In some cases, however, we found signif- icant damage deeper than it would be expected from the measured UVB penetration (see also Garcia-Pichel \& Castenholz 1994). This may be the result of a combination of factors unique to sedimentary ecosystems: a near-surface zone containing UV-absorbing organic components, high oxygen tensions (due to localized, high photosynthetic rates) and exposure to UV, which constitutes the right mixture for photosensitized and radical-mediated photooxidative reactions. The detrimental effects of UV may thus be locally enhanced and certain long-lived reactive oxygen species (singletoxygen, hydrogen peroxide) may diffuse down where little UV exposure exists, producing some additional indirect damage.

In summary, the exposure of microphytobenthic communities to ultraviolet radiation does not only depend on the optical transparency of the overlaying waters but also on the optical properties of the sediments themselves. The optics of the microbial photosynthetic communities we examined allowed UV to play a significant role in their functioning, not only in the case of bare substrates (hence in the colonization process), but even more so in well-formed, highly organic communities, such as microbial mats, where the impact of UV may be enhanced by synergistic effects of high concentration of photosensitizers and elevated oxygen tensions. Our results underscore the need, recently expressed by other investigators (Vincent \& Quesada 1994), to give serious consideration to benthic communities with regard to the ecological implications of increases of UVB due to stratospheric ozone depletion. Field experimentation is needed to establish the sensitivity of these communities to UVR. The extent to which biological adaptation to the physicochemical characteristics described above may prevent or counteract the detrimental role of UV in these communities remains largely to be explored. The use of sunscreen compounds and the regulation of organismal exposure through vertical migrations seem to be important, but not universal, adaptations to avoid excessive exposure.

Acknowledgements. We thank S. Neuer and L. Prufert for critically reading the manuscript and $M$. Kuhl, L. Prufert, L. Stal, and B. Thamdrup for samples. The authors were supported by stipends from the Max-Planck Soclety.

\section{LITERATURE CITED}

Bebout BM, Garcia-Pichel F (1995) UVB-induced vertıcal migratıons of cyanobacteria in a microbial mat. Appl Environ Microbiol 61:4215-4222

Bothwell ML, Sherbot DMJ, Pollock CM (1994) Ecosystem response to solar ultraviolet-B radiation: influence of trophic level interactions. Science 265:97-100

Garcia-Pichel F (1995) A scalar irradiance fiber-optic microprobe for the measurement of ultraviolet radiation at high 
spatial resolution. Photochem Photobiol 61:248-254

Garcia-Pichel F, Castenholz RW (1991) Characterization and biological implications of scytonemin, a cyanobacterial sheath pigment. J Phycol 27:395-409

Garcia-Pichel F, Castenholz RW (1993) Occurrence of UVabsorbing, mycosporine-like compounds among cyanobacterial isolates and an estimate of their screening capacity. Appl Environ Microbiol 59:163-169

Garcia-Pichel F, Castenholz RW (1994) On the significance of solar ultraviolet radiation for the ecology of microbial mats. In: Stal LJ, Caumette P (eds) Microbial mats. Structure, development and environmental significance. Springer-Verlag, Heidelberg, p 77-84

Grant J, Gust G (1987) Prediction of coastal sediment stability from photopigment content of mats of purple sulphur bacteria. Nature 330:244-246

Helbling EW, Villafane $V$, Holm-Hansen O (1994) Effects of ultraviolet radiation on Antarctic marine phytoplankton photosynthesis with particular attention to the influence of mixing. In: Weiler CS, Penhale PA (eds) Ultraviolet radiation in Antarctica: measurements and biological effects American Geophysical Union, Washington, DC, p 207-227

Holm-Hansen O, Helbling EW, Lubin D (1993) Ultraviolet radiation in Antarctica: inhibition of primary production. Photochem Photobiol 58:567-570

Jergensen. BB, Des Marais DJ (1988) Optical properties of benthic photosynthetic communities: fiber-optic studies of cyanobacterial mats. Limnol Oceanogr 33:99-113

Kirk JTO (1983) Light and photosynthesis in aquatic ecosystems. Cambridge University Press, Cambridge

Kühl M, Jørgensen BB (1994) The light field of microbenthic communities: radiance distribution and microscale optics of sandy coastal sediments. Limnol Oceanogr 39:1368-1398

This article was submitted to the editor
Lassen C, Ploug H, Jørgensen BB (1992) A fiber-optıc scalar Irradiance microsensor: application for spectral light measurements in sediments. FEMS Microbiol Ecol 86:247-254

Margulis L, Walker JCG, Rambler MB (1976) Reassessment of the roles of oxygen and ultaviolet light in Precambrian evolution. Nature 264:620-624

Patterson DM (1994) Microbiological mediation of sediment structure and behaviour. In: Stal LJ, Caumette P (eds) Microbial mats. Structure, development and environmental significance. Springer-Verlag, Heidelberg, p 97-109

Pınckney J, Zingmark R (1993) Modelling intertidal benthic microalgal annual production in estuarine ecosystems. J Phycol 29:396-407

Smith RC, Baker KS (1981) Optical properties of the clearest natural seawaters. Appl Optics 20:177-184

Smith RC, Prézelin BB, Baker KS, Bidigare RR, Boucher NP, Coley T, Karentz D, Maclntyre S, Matlick HA, Menzies D, Ondrusek M, Wan Z, Waters KJ (1992) Ozone depletion: ultraviolet radiation and phytoplankton biology in Antarctic waters. Science 255:952-959

Van Raalte C, Valiela I, Teal J (1976) Production of epibenthic salt marsh algae: light and nutrient limitation. Limnol Oceanogr 21:862-872

Vincent WF, Quesada A (1994) Ultraviolet radiation effects on cyanobacteria: implications for Antarctic microbial ecosystems. In: Weiler CS, Penhale PA (eds) UItraviolet radiation in Antarctica: measurements and biological effects. American Geophysical Union, Washington, DC, p 111-124

Vogelmann TC, Björn LO (1986) Plants as light traps. Physiol Plant 68:704-708

Vosjan JH, Pauptit E (1992) Penetration of photosynthetically available light (PAR). UV-a and UV-b in Admiralty Bay. King George Is., Antarctica. Circumpolar J 1-2:50-58

Manuscript first received: May 24, 1995

Revised version accepted: July 18, 1995 